\title{
Synthesis and photooxidation of styrene copolymer bearing camphorquinone pendant groups
}

\author{
Branislav Husár ${ }^{* 1}$, Norbert Moszner ${ }^{2}$ and Ivan Lukáč ${ }^{1}$
}

\section{Full Research Paper}

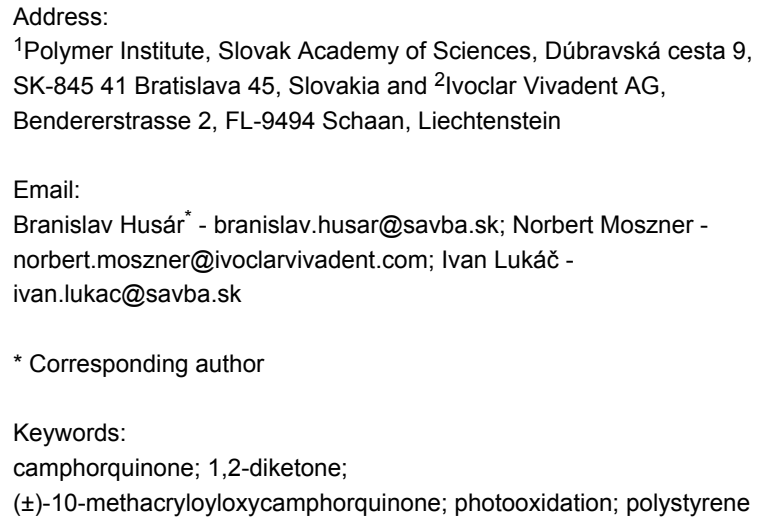

${ }^{1}$ Polymer Institute, Slovak Academy of Sciences, Dúbravská cesta 9, SK-845 41 Bratislava 45, Slovakia and 2Ivoclar Vivadent AG, Bendererstrasse 2, FL-9494 Schaan, Liechtenstein

\begin{abstract}
$( \pm)$-10-Methacryloyloxycamphorquinone (MCQ) was synthesized from ( \pm )-10-camphorsulfonic acid either by a known seven-step synthetic route or by a novel, shorter five-step synthetic route. MCQ was copolymerized with styrene (S) and the photochemical behavior of the copolymer $\mathbf{M C Q} / \mathbf{S}$ was compared with that of a formerly studied copolymer of styrene with monomers containing the benzil (BZ) moiety (another 1,2-dicarbonyl). Irradiation $(\lambda>380 \mathrm{~nm})$ of aerated films of styrene copolymers with monomers containing the $\mathbf{B Z}$ moiety leads to the insertion of two oxygen atoms between the carbonyl groups of $\mathbf{B Z}$ and to the formation of benzoyl peroxide (BP) as pendant groups on the polymer backbone. An equivalent irradiation of $\mathbf{M C Q} / \mathbf{S}$ led mainly to the insertion of only one oxygen atom between the carbonyl groups of camphorquinone (CQ) and to the formation of camphoric anhydride (11) covalently bound to the polymer backbone. While the decomposition of pendant BP groups formed in irradiated films of styrene copolymers with pendant $\mathbf{B Z}$ groups leads to crosslinking, only small molecular-weight changes in irradiated $\mathbf{M C Q} / \mathbf{S}$ were observed.
\end{abstract}

\section{Introduction}

Camphorquinone (CQ) in the presence of H-atom donors such as ethers ( $\mathrm{H}$ abstraction), or more efficiently tertiary amines (electron/proton transfer), is known to be an effective photoinitiator for curing methacrylate-based dental restorative resins [1-9]. CQ photochemistry in solution in the absence of oxygen [10-16] and in the presence of oxygen [10,13,17-20] has been studied extensively. In an inert atmosphere, the excited $n \rightarrow \pi^{*}$ triplet state of the carbonyl group of $\mathbf{C Q}$ abstracts an H-atom from a hydrogen donor. The two primarily formed radicals undergo subsequent reactions leading to photoproducts [21]. The rate-determining step in photoinitiation by $\mathbf{C Q} /$ amine is hydrogen transfer by the excited $n \rightarrow \pi^{*}$ triplet state of the carbonyl group of CQ from the alkylamino group [8,9]. The photochemistry of the low molecular CQ in the polystyrene (PS) film 
was the subject of previous studies $[21,22]$. It is reasonable to compare the photochemical properties of polymer-bound $\mathbf{C Q}$ with a polymer matrix containing another well-studied 1,2dicarbonyl compound, namely benzil (BZ). BZ can be converted almost quantitatively to benzoyl peroxide (BP) in an aerated polymer matrix by irradiation at $\lambda>400 \mathrm{~nm}$ (Scheme 1) $[23,24]$<smiles>O=C(C(=O)c1ccccc1)C1=CCCC=C1</smiles>

BZ<smiles>O=C(OOC(=O)c1ccccc1)c1ccccc1</smiles>

BP
Scheme 1: Photoperoxidation of BZ in an aerated glassy polymer matrix.

The pendant $\mathbf{B Z}$ groups of the styrene copolymers may be transformed into pendant $\mathbf{B P}$ groups $[25,26]$. Subsequent decomposition of BP pendant groups results in the formation of highly crosslinked films [27-30].

Owing to the interesting properties of styrene copolymers formed from BZ-containing monomers, a CQ-bearing monomer ( \pm )-10-methacryloyloxycamphorquinone (MCQ) (another monomer with a 1,2-dicarbonyl moiety) was prepared and copolymerized with styrene to give $\mathbf{M C Q} / \mathbf{S}$ copolymer bearing CQ pendant groups. Enantiopure MCQ is known from the literature [31]. The goal of this work was to prepare a more easily accessible racemic MCQ and to compare the photochemistry of MCQ/S with that of low molecular CQ in PS films in the presence of oxygen.

\section{Results and Discussion Synthesis of MCQ}

Racemic MCQ was synthesized in seven steps from ( \pm )-10camphorsulfonic acid (1) as a starting material in $18 \%$ overall yield (Scheme 2, see Supporting Information File 1 and Supporting Information File 2 for full experimental data). Total synthesis of $(1 R)$-10-methacryloyloxycamphorquinone from (1S)-10-camphorsulfonic acid [31] as well as of enantiopure stable intermediates 2-7 [8,32-34] are known. Though the physiological activity of optically active compounds depends on their configuration, the photochemical activity of CQ does not depend on the configuration. Without the need for an enantiopure product, the reaction economics could be improved both by the use of a cheaper racemic starting material and by a simplified multistep synthesis.

A shorter alternative synthetic route to 6 from 1 was proposed (Scheme 2, see Supporting Information File 1 and Supporting Information File 2 for full experimental data). ( \pm )-10-Iodocamphor (8) was prepared in one step from 1 with iodine and $\mathrm{PPh}_{3}$ in toluene under reflux in 39\% yield (lit. [35] 85\% yield). Compound 8 was selectively oxidized with $\mathrm{SeO}_{2}$ in bromobenzene under reflux to $( \pm)$-10-iodocamphorquinone (9) in $84 \%$ yield. A

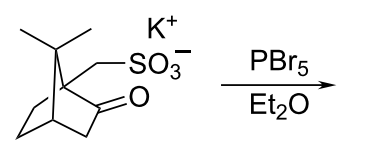

2

$\mathrm{K}_{2} \mathrm{CHO}_{3}$

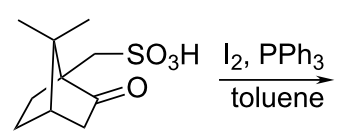

1

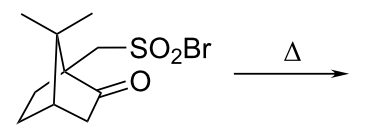

3<smiles>CC1(C)C2CCC1(CI)C(=O)C2</smiles>

$\underset{\mathrm{PhBr}}{\stackrel{\mathrm{SeO}_{2}}{\longrightarrow}}$
$\underset{\mathrm{AcOH}}{\mathrm{AcOK}}$

4<smiles>CC1(C)C2CCC1(CBr)C(=O)C2</smiles><smiles>CC1(C)C2CCC1(CI)C(=O)C2=O</smiles>

9

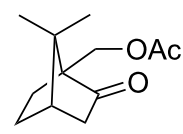

5<smiles>O=S(=O)(O)CC(Br)(Br)c1ccccc1</smiles>

$\underset{\mathrm{AcOH}}{\mathrm{AcOK}}$<smiles>CC(=O)OCC12CCC(C(=O)C1=O)C2(C)C</smiles>

6

$\downarrow \mathrm{HCl}$<smiles>C=C(C)C(=O)OCC12CCC(C(=O)C1=O)C2(C)C</smiles>

MCQ

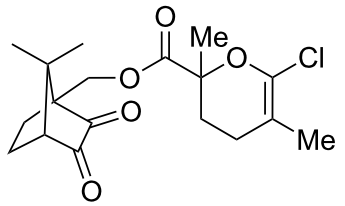

10<smiles>C=C(C)C(=O)OCC</smiles><smiles>CC1(C)C2CCC1(CO)C(=O)C2O</smiles>

7 
suspension of 9 in anhydrous acetic acid with freshly molten potassium acetate was heated to $170{ }^{\circ} \mathrm{C}$ for $8 \mathrm{~h}$ to provide 6 in $37 \%$ yield.

The advantage of this synthetic pathway lies in the reduction of synthetic steps as well as avoiding the use of rather expensive $\mathrm{PBr}_{5}$. Although we obtained MCQ in overall yield of only $5 \%$, optimization of conditions will likely provide a higher value. For example, iodocamphor 8 was previously obtained in $85 \%$ yield (much better than the $39 \%$ yield expressed here). Low yield in this step is blamed on the poor quality of reactants. The yield of $\mathbf{6}$ from 9 was lower due to the formation of side products. Thus, iodocamphor $\mathbf{8}$ should be transformed first to $\mathbf{5}$ and afterwards to 6 .

All attempts to transform 9 directly to MCQ were unsuccessful. For example, such a transformation was tested by stirring compound 9 at ambient temperature with the following reagents: Methacrylic acid/ $\mathrm{Cs}_{2} \mathrm{CO}_{3} / \mathrm{DMF}$, methacrylic acid/DBN/ benzene, methacrylic acid/NaH/n-hexane, methacrylic acid/ $\mathrm{NaHCO}_{3} / \mathrm{DMF}$, potassium methacrylate/acetone, and silver methacrylate/toluene.

From the last step of the MCQ synthesis, a side-product $\mathbf{1 0}$ was isolated and identified. It was previously reported that a commercial sample of methacryloyl chloride contains its oxaDiels-Alder dimer, responsible for the formation of $\mathbf{1 0}$ [36]. This side-product could be avoided by using freshly distilled methacryloyl chloride. A significant difference in the determined melting points of the racemates and enantiomers of 6,7 , and MCQ is caused by the configuration of these compounds (Table 1). The decrease of melting point of the racemate is $10-12{ }^{\circ} \mathrm{C}$ in the case of 6 and $43-45^{\circ} \mathrm{C}$ in the case of MCQ compared to the pure enantiomer. Racemic 7 melts over a broad range of temperatures in contrast to enantiomeric 7, which has a sharp melting point. The compounds in this work are racemates, but the corresponding compounds in the literature are pure enantiomers. The racemates can crystallize as a racemic mixture (lower mp), as a racemic compound (lower or higher $\mathrm{mp}$ ), or rarely as a racemic solid solution (slightly lower or higher $\mathrm{mp})$.

\section{Polymerization}

As introduced in Supporting Information File 1, the copolymer MCQ/S was synthesized by copolymerization of styrene (99.54 mol \%) and MCQ (0.46 mol \%), initiated by AIBN at $60{ }^{\circ} \mathrm{C}$ and resulting in $10 \%$ conversion. FTIR spectroscopy was used to estimate the content of CQ units in the MCQ/S copolymer by interpolation of the peak area of the carbonyl band (1740-1790 $\left.\mathrm{cm}^{-1}\right)$ using a calibration curve consisting of five different concentrations of $\mathrm{MCQ}$ in $\mathrm{CCl}_{4}$ solution. UV-vis spectroscopy was used in a similar way by interpolation of the $n \rightarrow \pi^{*}$ peak area (390-510 $\mathrm{nm}$ ) using a calibration curve. The content of MCQ units in MCQ/S copolymer was determined to be $0.72 \mathrm{~mol} \%$ from FTIR and $0.62 \mathrm{~mol} \%$ from UV-vis. MCQ is therefore more reactive than styrene, which is in agreement with the copolymerization parameters of structurally similar monomers.

\section{Photooxidation of MCQ/S}

Since it is difficult to follow the structural changes of the CQ structures of the MCQ/S copolymer during photochemical transformation, an analogous study with low molecular CQ doped in a PS matrix was first performed. Elucidation of the structures of low molecular photoproducts was conveniently followed by spectral methods [22] and by isolation from the polymer matrix followed by spectral identification [21]. The results of the CQ photooxidation in PS are summarized in Scheme 3 [21].

The addition of molecular oxygen to the excited $n \rightarrow \pi^{*}$ triplet state of ketones and 1,2-diketones to form 1,4-biradicals is a

\begin{tabular}{|c|c|c|c|c|}
\hline Compound & $\begin{array}{l}\text { Melting point of racemate } \\
\left({ }^{\circ} \mathrm{C}\right)\end{array}$ & $\begin{array}{l}\text { Melting point of enantiomer } \\
\left({ }^{\circ} \mathrm{C}\right)\end{array}$ & $\begin{array}{l}\text { Configuration of enantiomer } \\
(R \text { or } S)\end{array}$ & Reference \\
\hline 4 & $77-78$ & 78 & $S$ & [35] \\
\hline 4 & $77-78$ & 78 & $R$ & [32] \\
\hline 4 & $77-78$ & $76-78$ & $R$ & [8] \\
\hline 6 & $76-78$ & 88 & $R$ & [33] \\
\hline 6 & $76-78$ & $87-90$ & $R$ & [8] \\
\hline 7 & $\approx 100-255$ & $201-203$ & $R$ & [8] \\
\hline 7 & $\approx 100-255$ & 205 & $R$ & [34] \\
\hline 8 & $67-72$ & 71 & $S$ & [35] \\
\hline$M C Q$ & $46-49$ & $91-92$ & $R$ & [31] \\
\hline
\end{tabular}




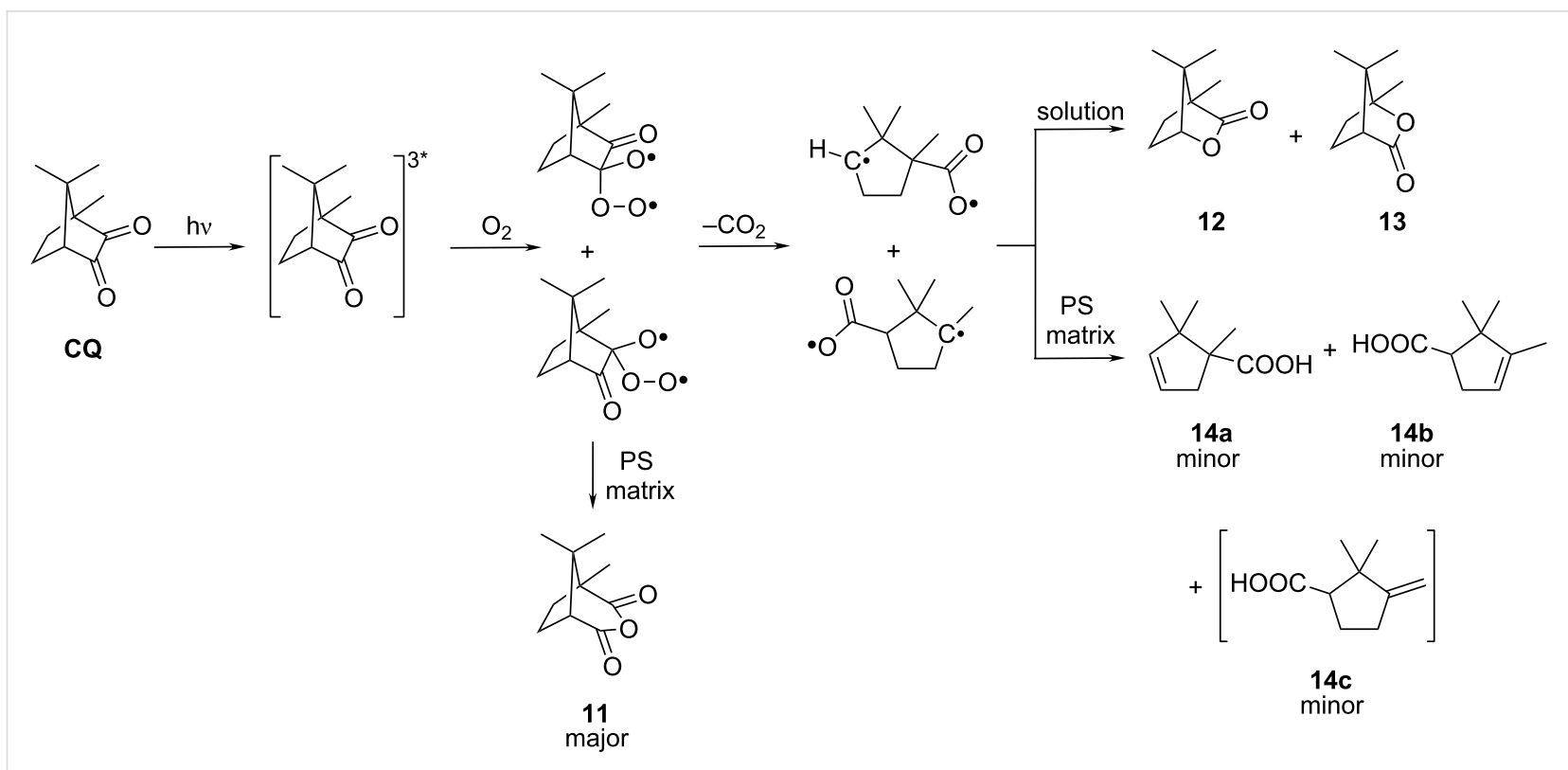

Scheme 3: Photooxidation of CQ in aerated glassy PS matrix.

generally accepted mechanism, which has been theoretically treated and reviewed [37]. The oxygen atom released during the formation of $\mathbf{1 1}$ can oxidize another molecule of $\mathbf{C Q}$ to 11. It is likely that common biradical intermediates are responsible for the formation of lactones $\mathbf{1 2}$ and $\mathbf{1 3}$ in solution [10] and acids 14a and 14b formed in the PS matrix [21]. The intramolecular recombination of biradical intermediates is favored in benzene solution. However, in glassy PS matrix the intramolecular abstraction of a hydrogen atom and formation of a double $\mathrm{C}=\mathrm{C}$ bond occurs. The glassy polymer matrix should retard the intramolecular recombination of biradicals.

During the irradiation of MCQ/S film at $\lambda>380 \mathrm{~nm}$ in air, the changes were followed by FTIR (Figure 1) and UV-vis (Figure 2) spectroscopy. The evolution of both spectra of low molecular CQ doped in the PS matrix and that of copolymer MCQ/S during irradiation (beside ester carbonyl absorption in FTIR spectra) are similar. Absorption bands of the CQ 1,2dicarbonyl group vibrations $\left(1776,1759 \mathrm{~cm}^{-1}\right)$ decreased quantitatively. This decrease is accompanied by the formation of bands at 1815 and $1770 \mathrm{~cm}^{-1}$ assigned to anhydride $\mathbf{1 1}$ (Figure 1). Increased absorption near $1700 \mathrm{~cm}^{-1}$ was assigned to acids 14. After thermal treatment of the irradiated MCQ/S film at $90{ }^{\circ} \mathrm{C}$ for $2 \mathrm{~h}$, no change was observed by FTIR spectroscopy. This signifies that no thermally unstable eightmember ring peroxide (in analogy with $\mathbf{B P}$ formed from $\mathbf{B Z}$ as shown in Scheme 1) was present in the PS matrix after irradiation. FTIR vibration bands for such cyclic diacylperoxide would be expected to be found near $1800 \mathrm{~cm}^{-1}$. Also in UV-vis spectra of the MCQ/S film after irradiation (Figure 2), complete

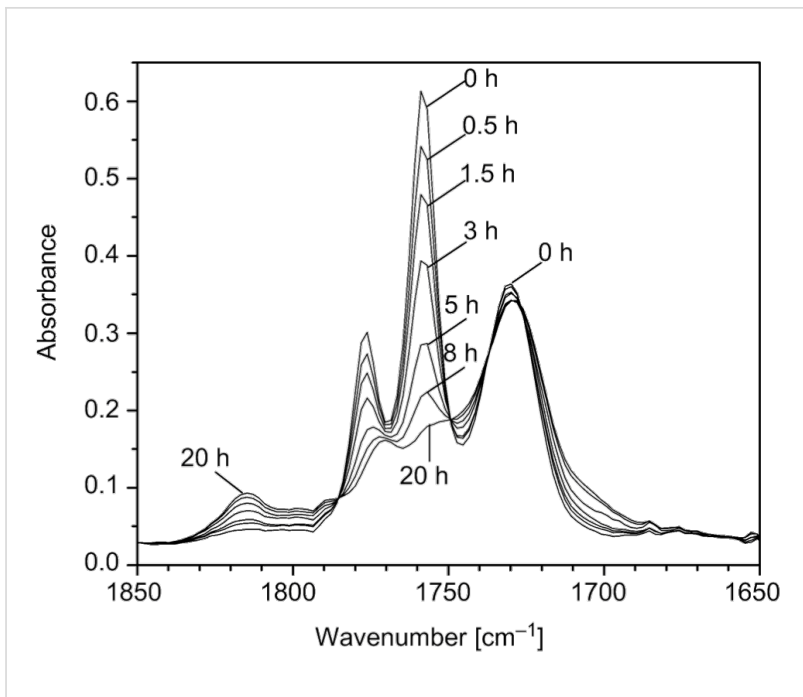

Figure 1: FTIR spectra of MCQ/S film after irradiation in a carousel for the indicated periods. Spectrum of PS film was subtracted.

reduction of the $n \rightarrow \pi *$ absorption band of the 1,2-dicarbonyl group of the CQ structure is seen.

The GC-MS results [21] allow the rough estimation of the distribution of CQ photooxidation products in PS from the GC record. About $54 \%$ of the whole area corresponds to 11 and its secondary products formed during isolation (secondary products are not formed in the MCQ/S film during irradiation). 16\% corresponds to $14 \mathbf{a}-\mathbf{c}$ and the remaining $30 \%$ are unidentified compounds. A similar distribution of products is most probably also present in the photooxidized MCQ/S copolymer. 


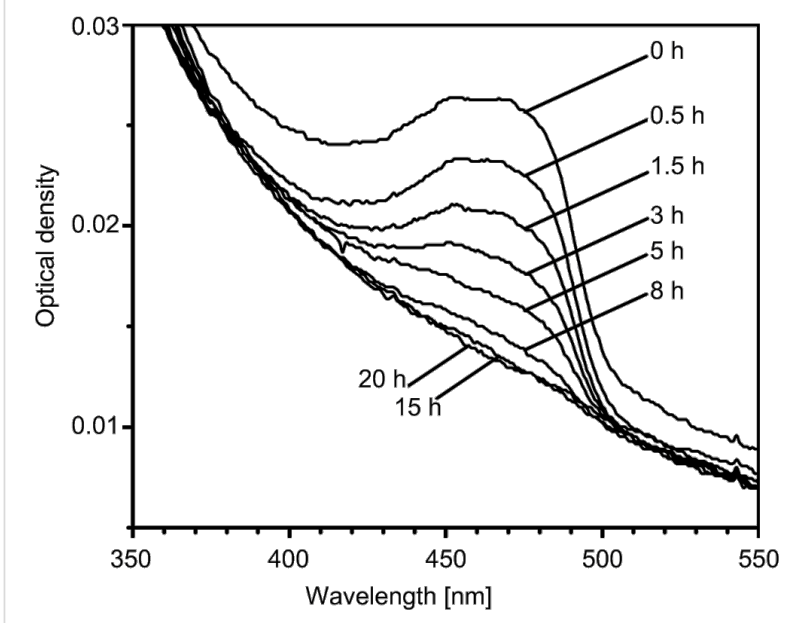

Figure 2: UV-vis spectra of MCQ/S film after irradiation in a carousel apparatus for the indicated periods.

Whereas the previously published irradiation of styrene copolymers with the monomers containing $\mathbf{B Z}\left(M_{\mathrm{n}}=84000, \mathrm{PD}=1.8\right)$ with $0.54 \mathrm{~mol} \%$ of the BZ-containing component led to extensive crosslinking with $69 \%$ gel fraction [21], MCQ/S with $0.72 \mathrm{~mol} \%$ of CQ moieties did not reach the gel point under the same conditions of irradiation; MCQ/S film retained its solubility in organic solvents. PS equivalent molar masses were then determined by GPC before and after irradiation. The molecular weights and polydispersities of the irradiated copolymer $\left(M_{\mathrm{n}}=190000, \mathrm{PD}=2.7\right)$ were higher than those of the initial copolymer $\left(M_{\mathrm{n}}=170000, \mathrm{PD}=2.0\right)$. Therefore, some recombi- nation of macroradicals occurred during irradiation. However, the crosslinking of styrene copolymers with the monomers containing $\mathbf{B Z}$ is significantly more efficient than those of $\mathrm{MCQ} / \mathrm{S}$.

While in the case of styrene copolymers with the monomers containing BZ decomposition of pendant BP groups produces only one polymeric benzoyloxy radical that is efficient in crosslinking, in the MCQ/S copolymer two acyloxy radicals could be produced from the postulated covalently bound cyclic diacylperoxide and could cause extensive crosslinking. As the changes in the chemical and molecular weights show, the mechanism of MCQ/S crosslinking (increase of molecular weight) is clearly different from that in the presence of $\mathbf{B Z}$ structures. Hence, the covalently bound cyclic diacylperoxide as an intermediate is most probably not formed. Similar to $\mathbf{B Z}$, the $n \rightarrow \pi^{*}$ triplet state of the CQ structure may also add molecular oxygen to form a 1,4-biradical. In the case of the $\mathbf{B Z}$ structures, formation of the 1,4-biradical is followed by $\mathbf{B P}$ formation. In comparison, CQ structures react with oxygen forming 1,4-biradicals, which decompose to camphoric anhydride 11 structures covalently bound to the polymer backbone (Scheme 4a). Liberated atomic oxygen during the formation of covalently bound 11 may oxidize another pendant CQ unit to the covalently bound 11. Cyclopentenecarboxylic acid $\mathbf{1 4}$ structures shown in Scheme 3 according to the low molecular study [21] were formed to a much lesser extent. Since the phototransformation of CQ to 11 is not quantitative, $n+m=99.7$; the remaining 0.3 consists of cyclopentenoic acids $\mathbf{1 4}$ and other unknown photoproducts.

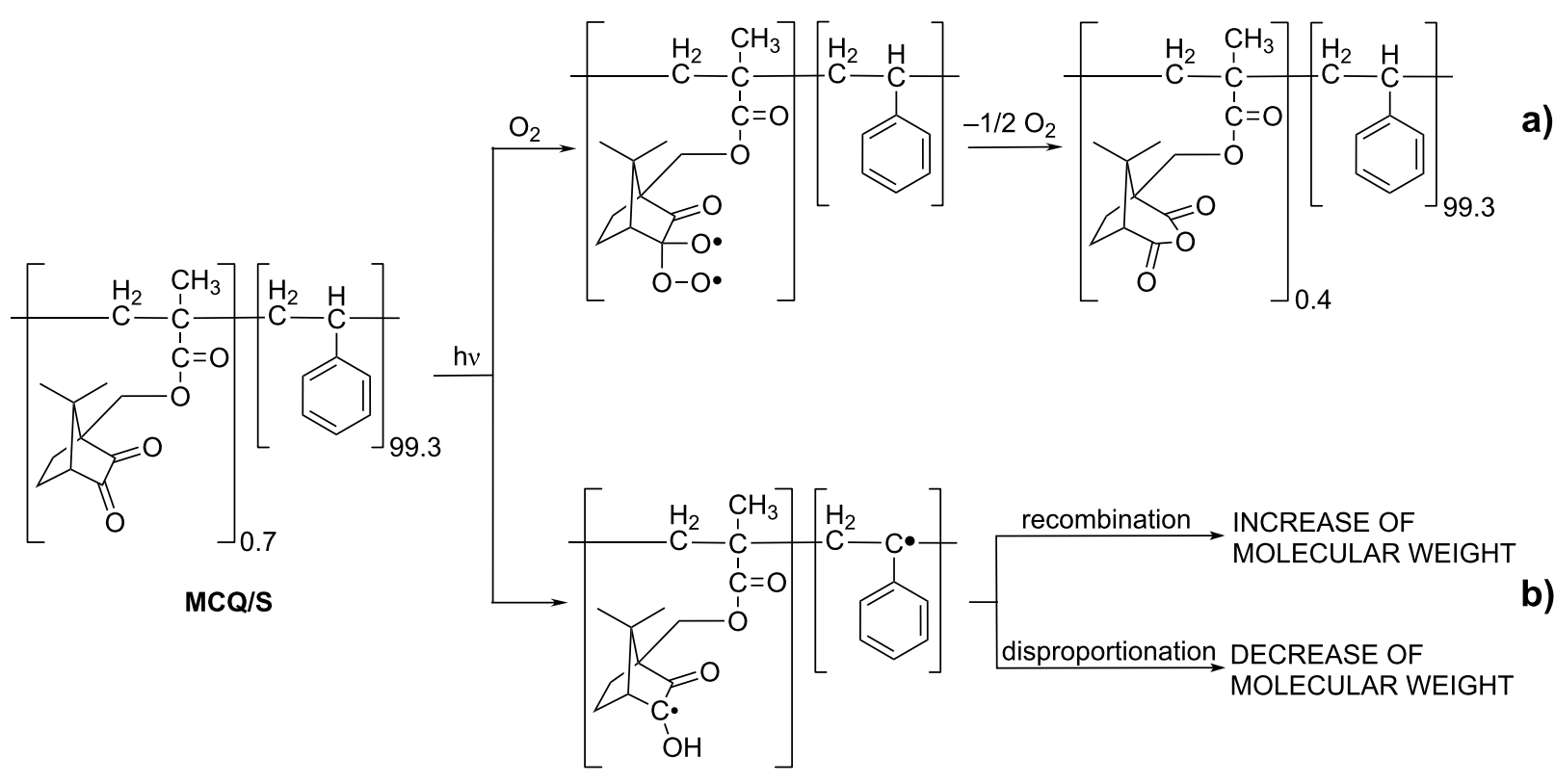


The increase of the molecular weight of $\mathbf{M C Q} / \mathbf{S}$ during irradiation under low oxygen conditions is induced primarily by an abstraction of hydrogen from the polymer backbone by the CQ structure in the triplet state under the formation of ketyl and alkyl radicals. The formed macroradicals can recombine and/or disproportionate (Scheme 4b). Recombination of macroradicals leads to an increase of the molecular weight and polydispersity. As previously shown, oxygen increases the consumption rate of CQ added to PS and lowers the rate of decrease of the molecular weight of PS [22]. Therefore in simultaneous photooxidation and photoreduction (Scheme 4) in the presence of oxygen, the intramolecular photooxidation of CQ has almost no effect on the molecular weight [21]. In the case of MCQ/S, photoreduction forms macroradicals that recombine causing an increase in the molecular weight.

\section{Conclusion}

Upon irradiation of $\mathbf{M C Q} / \mathbf{S}$ copolymer film by light with $\lambda>380 \mathrm{~nm}$ in air, the $\mathbf{C Q}$ structure in the copolymer was transformed mainly to pendant camphoric anhydride 11 structures. Also cyclopentenecarboxylic acid $\mathbf{1 4}$ structures covalently bound to copolymer backbone were identified to a minor extent. No cyclic camphordiacyl peroxide as an intermediate of the $\mathbf{C Q}$ photooxidation was found. Crosslinking of MCQ/S is inefficient compared to the case of styrene copolymers with monomers containing the $\mathbf{B Z}$ moiety.

Monomer MCQ (racemate) was synthesized from camphorsulfonic acid in seven steps by a known synthetic pathway for optically active MCQ. As an improvement, an alternative five-step synthesis of MCQ was proposed as well.

\section{Supporting Information}

Supporting information contains detailed experimental data for the synthesis of the compounds 2-10, MCQ, and copolymer MCQ/S, irradiation conditions, and NMR spectra of 5-10 and MCQ.

\section{Supporting Information File 1}

Experimental part.

[http://www.beilstein-journals.org/bjoc/content/ supplementary/1860-5397-8-37-S1.pdf]

\section{Supporting Information File 2}

NMR spectra of compounds 5-10 and MCQ.

[http://www.beilstein-journals.org/bjoc/content/ supplementary/1860-5397-8-37-S2.pdf]

\section{Acknowledgements}

Financial support from grants VEGA 2/0072/11 and APVV0562-07 is gratefully acknowledged. Authors sincerely thank Ms. Katarína Borská for GPC measurements, Mr. Jean-Louis Canet for MS measurements, and Mr. Samuel C. Ligon for reading the manuscript.

\section{References}

1. Mateo, J. L.; Bosch, P.; Lozano, A. E. Macromolecules 1994, 27, 7794-7799. doi:10.1021/ma00104a038

2. Munksgaard, E. C.; Irie, M.; Asmussen, E. J. Dent. Res. 1985, 64, 1409-1411. doi:10.1177/00220345850640121801

3. Cook, W. D. Polymer 1992, 33, 600-609. doi:10.1016/0032-3861(92)90738-I

4. Taira, M.; Urabe, H.; Hirose, T.; Wakasa, K.; Yamaki, M. J. Dent. Res. 1988, 67, 24-28. doi:10.1177/00220345880670010401

5. Fujimori, Y.; Kaneko, T.; Kaku, T.; Yoshioka, N.; Nishide, H.; Tsuchida, E. Polym. Adv. Technol. 1992, 3, 437-441. doi:10.1002/pat.1992.220030804

6. Inomata, K.; Minoshima, I.; Matsumoto, T.; Tokumaru, K. Polym. J. 1993, 25, 1199-1202. doi:10.1295/polymj.25.1199

7. Jakubiak, J.; Allonas, X.; Fouassier, J. P.; Sionkowska, A.; Andrzejewska, A.; Lindén, L. Å.; Rabek, J. F. Polymer 2003, 44, 5219-5226. doi:10.1016/S0032-3861(03)00568-8

8. Ullrich, G.; Herzog, D.; Liska, R.; Burtscher, P.; Moszner, N. J. Polym. Sci., Part A: Polym. Chem. 2004, 42, 4948-4963. doi:10.1002/pola.20318

9. Andrzejewska, E.; Lindén, L.-Å.; Rabek, J. F. Macromol. Chem. Phys. 1998, 199, 441-449. doi:10.1002/(SICI)1521-3935(19980301)199:3<441::AID-MACP441>3. $0 . \mathrm{CO} ; 2-\mathrm{N}$

10. Meinwald, J.; Klingele, H. O. J. Am. Chem. Soc. 1966, 88, 2071-2073. doi:10.1021/ja00961a056

11. Monroe, B. M.; Weiner, S. A.; Hammond, G. S. J. Am. Chem. Soc. 1968, 90, 1913-1914. doi:10.1021/ja01009a049

12. Monroe, B. M.; Weiner, S. A. J. Am. Chem. Soc. 1969, 91, 450-456. doi:10.1021/ja01030a041

13. Rubin, M. B.; LaBarge, R. G. J. Org. Chem. 1966, 31, 3283-3289. doi:10.1021/jo01348a041

14. Rubin, M. B. Tetrahedron Lett. 1969, 45, 3931-3934. doi:10.1016/S0040-4039(01)88579-8

15. Rubin, M. B.; Ben-Bassat, J. M. Tetrahedron 1970, 26, 3579-3589. doi:10.1016/S0040-4020(01)92937-0

16. Rubin, M. B.; Gutman, A. L. J. Org. Chem. 1986, 51, 2511-2515. doi:10.1021/jo00363a020

17. Gream, G. E.; Paice, J. C.; Ramsay, C. C. R. Aust. J. Chem. 1969, 22, 1229-1247. doi:10.1071/CH9691229

18. Bredt-Savelsberg, M.; Zaunbrecher, K.; Knieke, L. Chem. Ber. 1927, 60, 1801-1808. doi:10.1002/cber.19270600813

19. Bredt-Savelsberg, M. Chem. Ber. 1932, 65, 1-11. doi:10.1002/cber.19320650102

20. Ji, S.-J.; Lu, J.; Lang, J.-P.; Horiuchi, C. A. Synth. Commun. 2002, 32, 1659-1663. doi:10.1081/SCC-120004256

21. Husár, B.; Lukáč, I. J. Photochem. Photobiol., A 2011, 223, 189-193. doi:10.1016/j.jphotochem.2011.08.017

22. Mosnáček, J.; Lukáč, I. J. Photochem. Photobiol., A 2002, 151, 95-104. doi:10.1016/S1010-6030(02)00024-2 
23. Lukáč, I.; Kósa, C. Macromol. Rapid Commun. 1994, 15, 929-934. doi:10.1002/marc.1994.030151204

24. Kósa, C.; Lukáč, I.; Weiss, R. G. Macromol. Chem. Phys. 1999, 200, 1080-1085. doi:10.1002/(SICI)1521-3935(19990501)200:5<1080::AID-MACP1080> 3.0.CO;2-7

25. Husár, B.; Lukáč, I. J. Photochem. Photobiol., A 2008, 195, 191-197. doi:10.1016/j.jphotochem.2007.10.001

26. Husár, B.; Commereuc, S.; Chmela, Š.; Verney, V. Polym. Int. 2010, 59, 1563-1570. doi:10.1002/pi.2901

27. Kósa, C.; Lukáč, I.; Weiss, R. G. Macromolecules 2000, 33, 4015-4022. doi:10.1021/ma991493z

28. Mosnáček, J.; Weiss, R. G.; Lukáč, I. Macromolecules 2002, 35, 3870-3875. doi:10.1021/ma0117458

29. Mosnáček, J.; Weiss, R. G.; Lukáč, I. Macromolecules 2004, 37, 1304-1311. doi:10.1021/ma030213j

30. Mosnáček, J.; Lukáč, I.; Chromik, Š.; Kostič, I.; Hrdlovič, P J. Polym. Sci., Part A: Polym. Chem. 2004, 42, 765-771. doi:10.1002/pola.10860

31. Angiolini, L.; Caretti, D.; Salatelli, E. Macromol. Chem. Phys. 2000, 201, 2646-2653. doi:10.1002/1521-3935(20001201)201:18<2646::AID-MACP2646>3.0. CO;2-D

32. Dallacker, F.; Alroggen, I.; Krings, H.; Laurs, B.; Lipp, M. Justus Liebigs Ann. Chem. 1961, 647, 23-36. doi:10.1002/jlac.19616470105

33. Dallacker, F.; Ulrichs, K.; Lipp, M. Justus Liebigs Ann. Chem. 1963, 667, 50-55. doi:10.1002/jlac.19636670108

34. Połoński, T.; Dauter, Z. J. Chem. Soc., Perkin Trans. 1 1986, 1781-1788. doi:10.1039/P19860001781

35. Sell, T.; Laschat, S.; Dix, I.; Jones, P. G. Eur. J. Org. Chem. 2000, 4119-4124. doi:10.1002/1099-0690(200012)2000:24<4119::AID-EJOC4119>3.0.C O;2-X

36. Fischer, W.; Belluš, D.; Alder, A.; Francotte, E.; Roloff, A. Chimia 1985 , 39, 19-20.

37. Nau, W. M. J. Inf. Recording 1998, 24, 105-114.

\section{License and Terms}

This is an Open Access article under the terms of the Creative Commons Attribution License (http://creativecommons.org/licenses/by/2.0), which permits unrestricted use, distribution, and reproduction in any medium, provided the original work is properly cited.

The license is subject to the Beilstein Journal of Organic Chemistry terms and conditions: (http://www.beilstein-journals.org/bjoc)

The definitive version of this article is the electronic one which can be found at: doi:10.3762/bjoc. 8.37 